\title{
Comparison of Eight Month Coastal Polluted Porcelain and Epoxy Resin Outdoor Insulators
}

\author{
${ }^{1}$ Waluyo, ${ }^{2}$ Ngapuli I. Sinisuka, ${ }^{2}$ Parouli M. Pakpahan, \\ ${ }^{2}$ Suwarno \& ${ }^{3}$ Maman A. Djauhari \\ ${ }^{1}$ Doctoral Student, Power Electric Scientific Group, STEI \\ ${ }^{2}$ Academic Staff, Power Electric Scientific Group, STEI \\ ${ }^{3}$ Research Group on Statistics, Department of Mathematics \\ Bandung Institute of Technology, Jl. Ganesha No. 10 Bandung 40132 Indonesia
}

\begin{abstract}
This study presents the experimental results of eight months naturally coastal polluted outdoor porcelain and epoxy resin insulators. The experiments were leakage current and applied high voltage measurements used a two-channel storage digital oscilloscope, in the hermetically sealed chamber, where temperature, humidity, pressure and applied voltage could be adjusted and measured simultaneously. The leakage current waveforms were analyzed using FFT and the relation to environmental parameters were analyzed using correlation matrix of multivariate statistical tools. It was also conducted SEM and EDAX tests.
\end{abstract}

Base on the correlation coefficient matrix, the humidity contributed to leakage current amplitude and phase angle on the porcelain insulator were very significant, with the correlation coefficient were 0.60 and -0.68 respectively. Whereas, on polluted epoxy resin insulator, the humidity did not influence to leakage current and phase angle considerably. Generally, the surface became rougher than the new one. The most three chemical elements in pollutants were chlorine, silicon and ferrum.

Keywords: epoxy resin; humidity; insulator; leakage current; phase angle; porcelain.

\section{Introduction}

Overhead transmission or distribution lines are widely used in present power system to transmit electric power from generation stations to customer points. Their proper function depends to a large extent on the insulation system with the supporting structures [1]. The performance of outdoor insulators, as main insulating materials, is affected by some parameters. One of these parameters is environmental pollution, whether its severity or chemical compositions.

The pollution flashover process of insulators is greatly influenced by the insulator's surface properties. Two surface conditions are recognised, either hydrophilic or hydrophobic. A hydrophilic surface is generally associated with ceramic insulators, such as porcelain insulators, whereas a hydrophobic surface 
is generally associated with polymeric insulators. Under wet conditions - such as rain, mist, etc., hydrophilic surfaces will wet out completely so that an electrolyte film covers the insulator [2].

One can summarise the whole process as an interaction between the insulator, pollutants, wet conditions, and applied voltage. Thus, for a better understanding of insulator pollution, wetting and the flashover process, some terms should be studied. Some terms related to this case are the local climate and environmental (pollution) conditions surrounding the insulator with emphasis on wetting, pollution sources and type of pollution, and leakage current flowing over the surface of insulator [2].

The performance of insulator under contaminated conditions is the underlying factor that determines insulation design for outdoor application. Contamination play an important role in every outdoor insulator application. This fact was recognized since the very beginning of outdoor power delivery. Today, there are standardized contamination test for porcelain and glass insulators, but not for composite insulators. There are instances where discrepancies between laboratory predictions and field experience arise. Thus, it is important to have a good understand the advantages and limitations of laboratory testing, in order to develop more sensible tests for ceramic and nonceramic insulators [3].

One of typical source of insulator pollutants is marine or coast [4]. Indonesia has the longest of coastal line in the world. Usually, a coastal region is passed through by electric power transmission or distribution lines, including switchyard. Thus, it is important to take a sample of polluted porcelain insulator as ceramic sample, and epoxy resin insulator as non-ceramic sample from a place near the coast for research. Nevertheless, the environmental variation of humidity, temperature and pressure were simulated in the laboratory.

The objectives of research are to obtain the comparison of leakage current properties between eight-month coastal polluted porcelain and epoxy resin insulators on various relative humidities, temperatures, pressures and applied voltages. These properties are amplitudes, waveforms and phase angles of leakage current. They are tools of assessment of outdoor insulator performance. The relations among the properties to environmental parameters are analyzed using correlation coefficient matrix of multivariate statistical tool. Thus, it can be understood how much each variable influence to another. As addition, it is presented SEM test results of specimen insulator surfaces and pollutants, and chemical element analysis of pollutants using EDAX. 


\section{Experimental and Analysis Methods}

These experiments were conducted on two $20 \mathrm{kV}$ outdoor insulators. One type was porcelain, and another one was epoxy resin. The insulators were naturally coastal polluted, which have been installed at PLN switchyard of Pangandaran, West Java, just around $600 \mathrm{~m}$ from the beach, on December $15^{\text {th }}, 2006$, and then taken on August 21 $1^{\text {st }}, 2007$.

Both insulators were tested in a hermetically sealed chamber, where temperature, humidity, pressure and applied high voltage could be adjusted and measured simultaneously. The size of the chamber was $120 \mathrm{~cm}$ x $150 \mathrm{~cm} \times 120$ $\mathrm{cm}(\mathrm{WxHxD})$. The measurements of leakage current and applied high voltage waveforms used a $100 \mathrm{MHz}$ two-channel storage digital oscilloscope. The measured data could be recorded and transferred to a computer using USB (Universal Serial Bus) and could be saved in softcopy form. The data could be read and saved in Excel and Bitmap forms. The schematic diagram of experimental setup is shown on Figure 1.

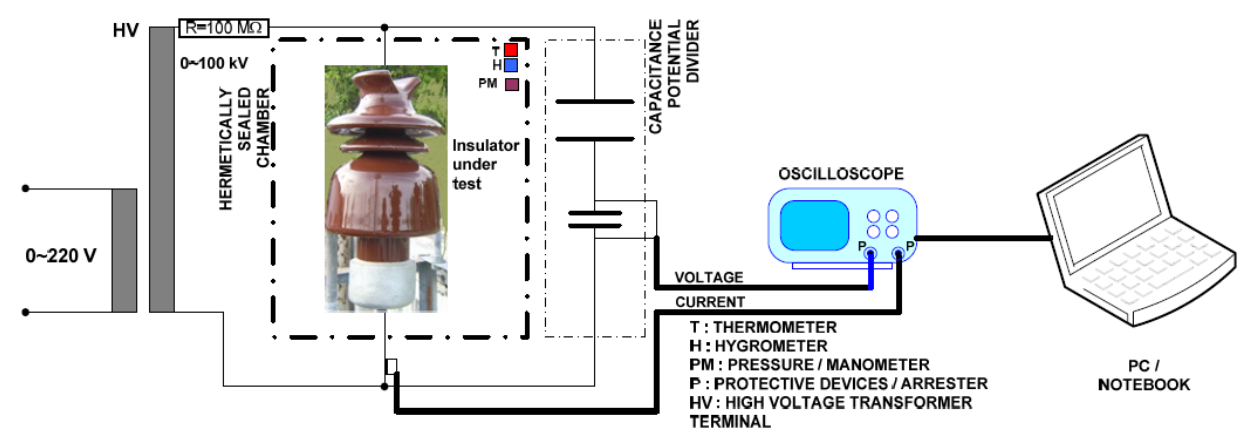

Figure 1 Schematic diagram of experimental setup.

Furthermore, the leakage current waveforms were analyzed using fast Fourier transform, so that it would be obtained amplitudes of harmonics. Finally, total harmonic distortion (THD) is defined as the total ratio of the harmonic component amplitudes and the fundamental amplitudes, which it can be expressed as below [5].

$$
T H D=\frac{\sqrt{\sum_{n=2}^{\tilde{N} I_{n}^{2}}}}{I_{1}}
$$

where $I_{n}$ is nth appear harmonic amplitudes, which in this case it is first to thirteenth odd harmonics, because they appeared dominantly. Otherwise, $I_{1}$ is fundamental harmonic amplitude. 
Thus, the frequency spectra were obtained on various conditions of insulators. These implementations used the Danielson-Lanczos method [6]. Whereas the relation of leakage current properties to environmental parameters were analyzed using correlation coefficient matrix of multivariate statistical tools. The correlation matrix is derivation of covariance matrix to understand how much level of correlation among variables or parameters, as follows $[7,8]$.

$$
\operatorname{Cov}(X, Y)=\frac{1}{n} \sum_{j=1}^{n}\left(x_{j}-\mu_{x}\right)\left(y_{j}-\mu_{y}\right)
$$

Thus, the components of correlation coefficient matrix as below.

$$
\rho_{x, y}=\frac{\operatorname{Cov}(X, Y)}{\sigma_{x} \cdot \sigma_{y}}
$$

where $\mathrm{X}$ and $\mathrm{Y}$ are variables $\mathrm{X}$ and $\mathrm{Y}$ respectively, that is covariance between variable $X$ and $Y, x_{j}$ and $y_{j}$ are $j^{\text {th }}$ data of $X$ and $Y$ variables respectively, $\mu_{x}$ and $\mu_{y}$ are mean data of $X$ and $Y$ variables, $\sigma_{x}$ and $\sigma_{y}$ are data variance of $X$ and $Y$ variables respectively.

The values of correlation matrix components are between -1 up to 1 . If a value close to -1 , it represents that one parameter highly influences to another, but it is reciprocal property. Otherwise, if a value close to 1 , it reveals that one parameter highly proportional influences to another. Finally, if a value close to zero, it is minor in dependency.

It is also shown the test results of SEM (scanning electron microscope) for both new-clean and polluted insulator specimens, and pollutants stuck on insulator surfaces. Besides that, it is indicated the major chemical element contained in the pollutants using EDAX (Energy Dispersive Analysis of X-rays) tests.

\section{Result and Discussion}

\subsection{Polluted Porcelain Insulator}

In this manuscripts, it is shown two main conditions of leakage current measurement results as sample, i.e. dry and wet conditions. In dry hermetically sealed chamber condition, as first sample, the waveform of typical leakage current measurement in bitmap form is shown on Figure 2. This waveform was obtained on condition of relative humidity, temperature, pressure and maximum applied voltage were $71 \%, 42.4^{\circ} \mathrm{C}, 0.2 \mathrm{kPa}$ and $55.4 \mathrm{kV}$ respectively. This waveform is not so significantly different from that the previous dry condition 
of new-clean porcelain insulator. Thus, in dry condition, the pollutants stuck on porcelain insulator surface did not influence leakage current significantly.

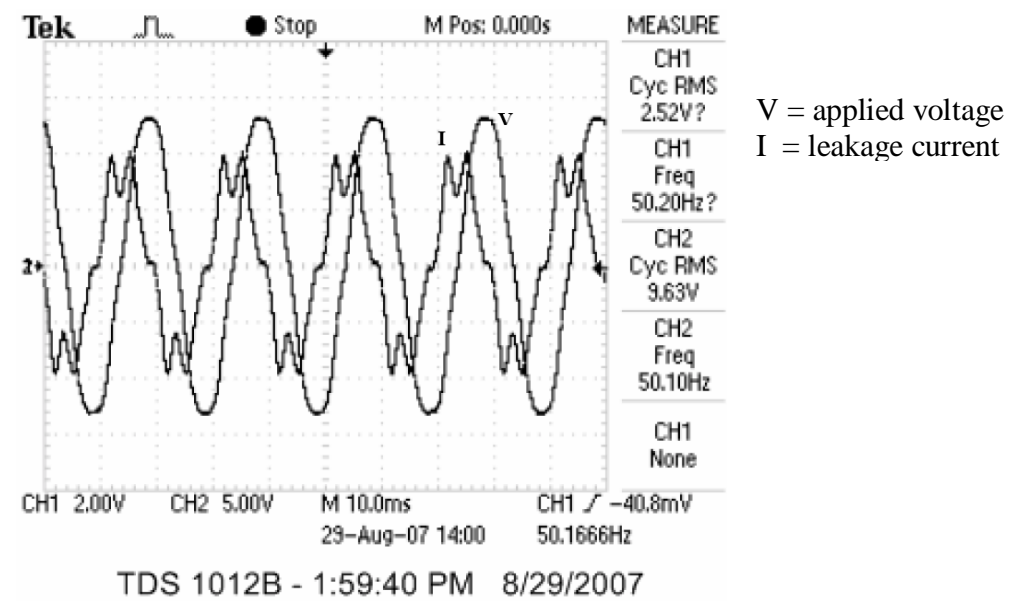

Figure 2 Bitmap form of applied voltage and leakage current waveforms of dry polluted porcelain insulator.

Whereas Figure 3 is Excel graphical form of applied voltage and leakage current waveforms of polluted insulator on that condition. The applied voltage is pure sinusoidal waveform, that the magnitude values are mentioned on the right side. Otherwise, the magnitude values of leakage current wave are indicated on the left side. Based on this leakage current waveform, it will be analyzed the frequency spectrum using fast Fourier transform.

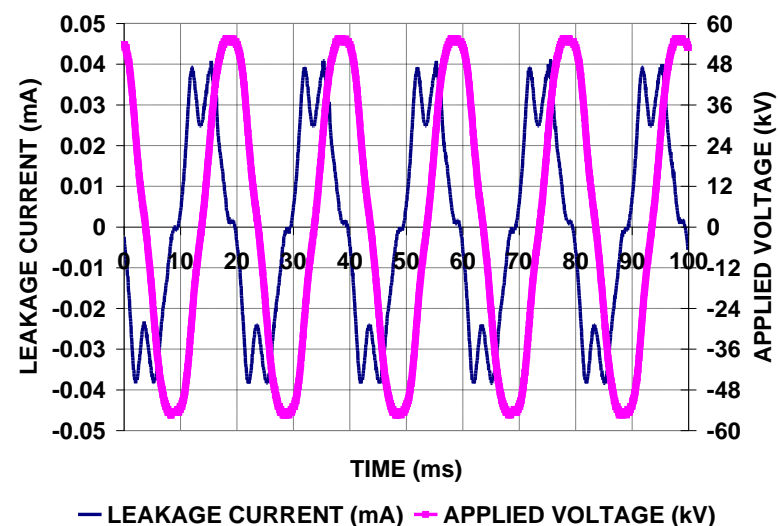

Figure 3 Excel graphical form voltage and leakage current waveforms of dry polluted porcelain insulator. 
Figure 4 shows the frequency spectrum of leakage current waveform of Figure 3. On this condition, the first to thirteenth odd harmonics are $80.15 \%, 0.97 \%$, $17.94 \%, 5.2 \%, 0.27 \%, 1.6 \%, 0.39 \%$ respectively compared to the leakage current amplitude. The third harmonic is very small, so that it still operated normally. Otherwise, the total harmonic distortion (THD) is $23 \%$, so that it is also normal condition.

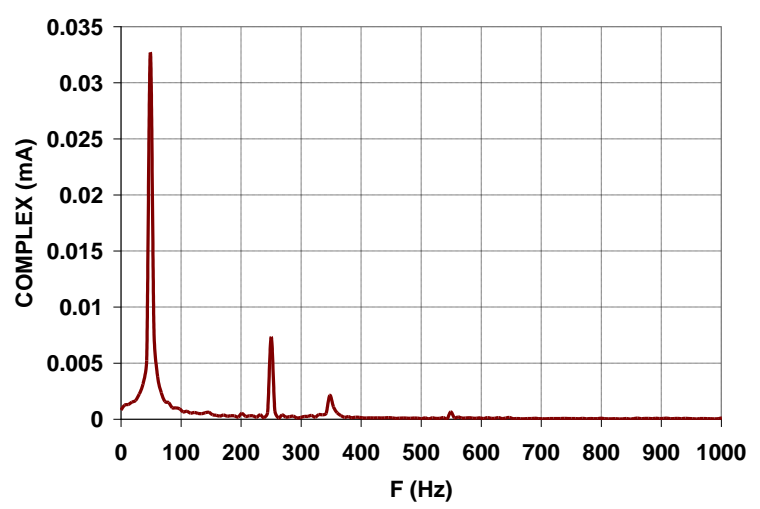

Figure 4 Frequency spectrum of leakage current waveforms of Figure 3.

On other condition, Figure 5 shows bitmap form of leakage current and applied voltage waveforms on polluted insulator due to $99 \%, 26^{\circ} \mathrm{C},-0.8 \mathrm{kPa}$ and 10.9 $\mathrm{kV}$ of relative humidity, temperature, pressure and maximum applied voltage respectively. Furthermore, Figure 6 is its Excel graphical form. This is as sample of wet condition.

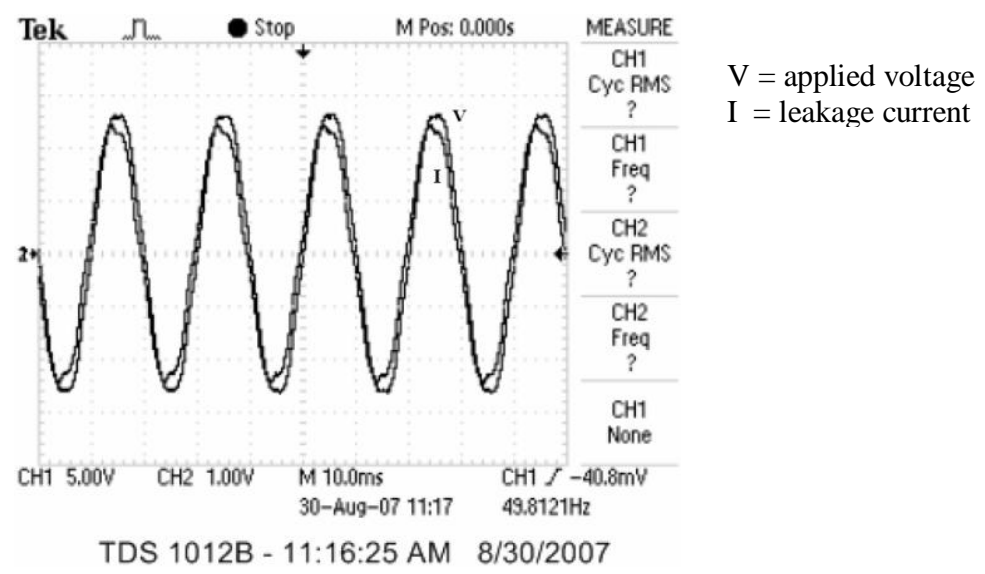

Figure 5 Bitmap form of applied voltage and leakage current waveforms of wet polluted porcelain insulator. 
The applied voltage is pure sinusoidal waveform, that the magnitude values are mentioned on the right side. Otherwise, the magnitude values of leakage current wave are indicated on the left side. In this condition, the phase difference between leakage current and applied voltage waves is 12.2 degree. This drastically reduces rather than that the new-clean porcelain insulator. In other word, the leakage current wave tends to close for coinciding close to pure sinusoidal waveforms. This means that the insulator was significantly more resistive compared to previous one.

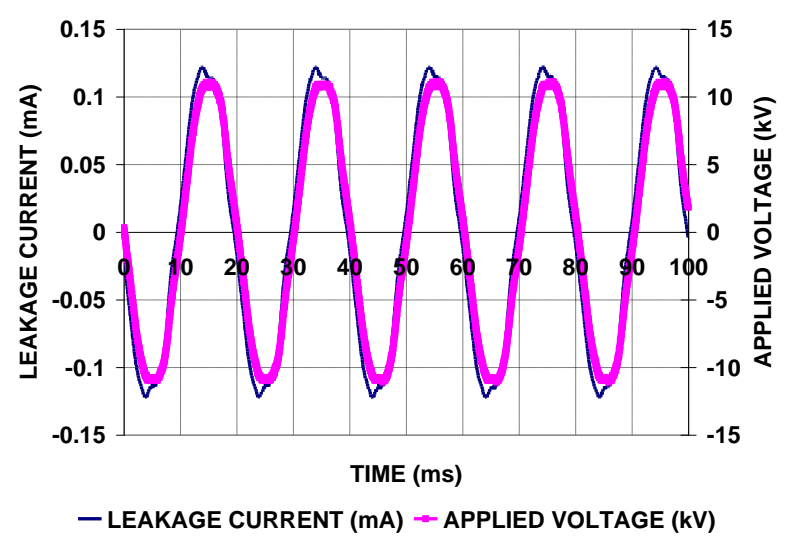

Figure 6 Applied voltage and leakage current waveforms of wet polluted porcelain insulator.

Based on this leakage current waveform, it will be analyzed the frequency spectrum using fast Fourier transform. Figure 7 represents the frequency spectrum of leakage current waveform on Figure 12. The first to thirteenth odd harmonics are $95.15 \%, 1.11 \%, 5.1 \%, 0.97 \%, 0.52 \%, 0.77 \%$ and $0.36 \%$ respectively compared to leakage current amplitude. The total harmonic distortion (THD) is only 6\%. These reasonable due to the leakage current waveform tends to close pure sinusoidal wave. This is the most resistive and conductive among previous conditions. The resistive condition is indicated by the phase difference between leakage current and applied voltage waves, and THD are very small. Whereas, the conductive condition is indicated by high amplitude of leakage current. 


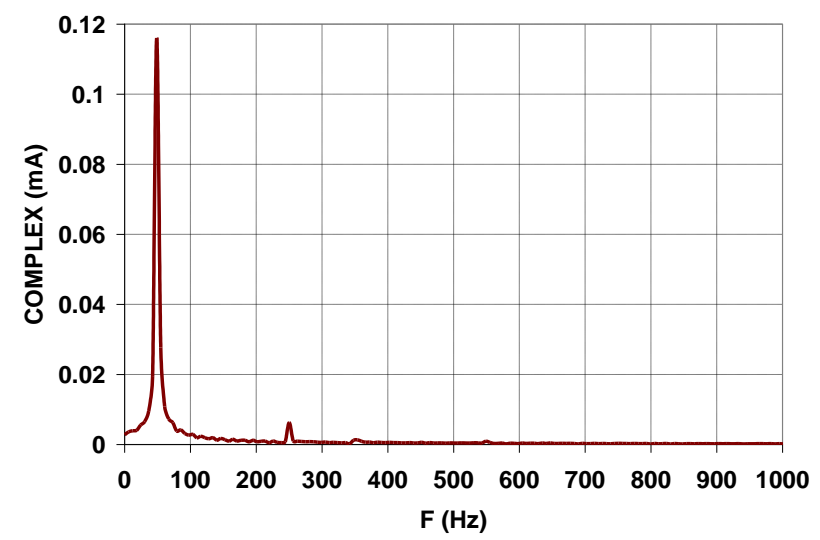

Figure 7 Frequency spectrum of leakage current waveforms of Figure 6

The behaviours of parameters on the measurements of polluted porcelain insulator are shown on Table 1. Based on this correlation matrix, the relative humidity considerably influences to the maximum leakage current magnitude and the phase difference between leakage current and applied voltage. These are $60 \%$ and $-68 \%$ respectively. This gives explanation that the relative humidity enhanced the maximum leakage current very significantly. This is also supported by the negative value of correlation component between applied voltage and leakage current. This indicates that the leakage current is dominantly influenced by relative humidity, rather than applied voltage, although the leakage current existence due to applied voltage technically. As addition, the relative humidity influences to phase difference also considerably, that the correlation coefficient is $-68 \%$. The phase difference will reduce as the relative humidity increases. First to last columns are maximum applied voltage, maximum leakage current, relative humidity, temperature, pressure, phase difference between leakage current and applied voltage waves, cosine of phase difference, first to thirteenth odd harmonics, and total harmonic distortion (THD) respectively. The actual data of pressure in chamber were positive and negative. The positive pressure means the chamber was compressed, and the negative pressure means the chamber was sucked, using electric pumps. Generally, on the actual data, the phase difference between leakage current and applied voltage will reduce as the relative humidity increases. Table 1 express the correlation matrix among variables of measurements on the coastal polluted insulator. 
Table 1 The levels of correlation among parameters on the polluted porcelain insulator.

\begin{tabular}{|c|c|c|c|c|c|c|c|c|c|c|c|c|c|c|c|}
\hline Variables & $V_{\max }$ & $I_{\max }$ & H & $\mathrm{T}$ & $\mathrm{P}$ & $\theta$ & $\begin{array}{c}\cos \\
(\Theta)\end{array}$ & $\mathrm{H} 1$ & $\mathrm{H} 3$ & H5 & H7 & $\mathrm{H} 9$ & H11 & $\mathrm{H} 13$ & THD \\
\hline $\mathrm{V}_{\max }$ & 1.00 & -0.84 & -0.67 & 0.34 & 0.00 & 0.97 & -0.97 & -0.85 & -0.80 & 0.15 & 0.77 & -0.82 & -0.28 & -0.86 & 0.98 \\
\hline$I_{\max }$ & -0.84 & 1.00 & 0.60 & -0.42 & 0.09 & -0.90 & 0.89 & 1.00 & 0.99 & 0.39 & -0.42 & 0.98 & 0.47 & 0.96 & -0.89 \\
\hline $\mathrm{H}$ & -0.67 & 0.60 & 1.00 & -0.56 & -0.19 & -0.68 & 0.66 & 0.60 & 0.53 & -0.03 & -0.50 & 0.57 & 0.19 & 0.59 & -0.66 \\
\hline $\mathrm{T}$ & 0.34 & -0.42 & -0.56 & 1.00 & -0.14 & 0.41 & -0.43 & -0.41 & -0.37 & -0.22 & & -0.45 & -0.28 & -0.39 & 0.42 \\
\hline P & 0.00 & 0.09 & -0.19 & -0.14 & 1.00 & -0.01 & 0.01 & 0.09 & 0.11 & 0.06 & 0.00 & 0.09 & -0.10 & 0.00 & -0.03 \\
\hline$\theta$ & 0.97 & -0.90 & -0.68 & 0.41 & -0.01 & 1.00 & -1.00 & -0.91 & -0.86 & -0.03 & 0.69 & -0.87 & -0.36 & -0.90 & 1.00 \\
\hline $\cos (\theta)$ & -0.97 & 0.89 & 0.66 & -0.43 & 0.01 & -1.00 & 1.00 & 0.89 & 0.84 & 0.02 & -0 & 0.86 & 0.39 & 0.89 & -1.00 \\
\hline $\mathrm{H} 1$ & -0.85 & 1.00 & 0.60 & -0.41 & 0.09 & -0.91 & 0.89 & 1.00 & 0.99 & 0.37 & -0.44 & 0.97 & 0.46 & 0.96 & -0.89 \\
\hline H3 & -0.80 & 0.99 & 0.53 & -0.37 & 0.11 & -0.86 & 0.84 & 0.99 & 1.00 & 0.42 & -0.40 & 0.97 & 0.42 & 0.94 & -0.84 \\
\hline H5 & 0.15 & 0.39 & -0.03 & -0.22 & 0.06 & -0.03 & 0.02 & 0.37 & 0.42 & 1.00 & 0.57 & 0.40 & 0.49 & 0.31 & 0.02 \\
\hline H7 & 0.77 & -0.42 & -0.50 & 0.08 & 0.00 & 0.69 & -0.67 & -0.44 & -0.40 & 0.57 & 1.00 & -0.35 & 0.27 & -0.42 & 0.69 \\
\hline $\mathrm{H} 9$ & -0.82 & 0.98 & 0.57 & -0.45 & 0.09 & -0.87 & 0.86 & 0.97 & 0.97 & 0.40 & -0.35 & 1.00 & 0.53 & 0.95 & -0.86 \\
\hline H11 & -0.28 & 0.47 & 0.19 & -0.28 & -0.10 & -0.36 & 0.39 & 0.46 & 0.42 & 0.49 & 0.27 & 0.53 & 1.00 & 0.45 & -0.36 \\
\hline & -0.86 & 0.96 & 0.59 & -0.39 & 0.00 & -0.90 & 0.89 & 0.96 & 0.94 & 0.31 & -0.42 & 0.95 & 0.45 & 1.00 & -0.89 \\
\hline THD & 0.98 & -0.89 & -0.66 & 0.42 & -0.03 & 1.00 & -1.00 & -0.89 & -0.84 & 0.02 & 0.69 & -0.86 & -0.36 & -0.89 & 1.00 \\
\hline
\end{tabular}

Otherwise, the leakage current amplitude influences to phase angle very significantly, that is $-90 \%$. The phase angle will reduce as the leakage current amplitude increases. Base on above explanation, the leakage current of polluted insulator is dominantly influenced by relative humidity. Furthermore, the leakage current magnitude affects to phase angle very significantly. This indicates that on high relative humidity, the polluted insulator had resistivecapacitive non-linear characteristic property. This was occurred due to porcelain insulator property susceptible to pollution and humidity.

Generally, the leakage current amplitude will reduce as temperature rises. Technically, a high temperature existence will reduce the relative humidity, that the leakage current magnitude will consequently reduce. The high temperature also raise the phase angle. In other word, in high temperature, the insulators will be more capacitive rather than in low temperature, due to relative humidity. However, the rate of capacitive property to the temperature was higher on polluted insulator rather than that on new-clean insulator.

Nevertheless, usually the magnitude value of phase angle is higher on the newclean porcelain insulator rather than on the polluted one, in same condition of relative humidity. This is also indicated that the polluted insulator was more resistive than the new-clean one.

Practically, on this -4 up to $5 \mathrm{kPa}$ range, the pressure did not influence to leakage current or phase angle. This is indicated by components of matrix correlated to pressure parameter as very low value. The complete data of 
measurements on coastal polluted porcelain insulator on this condition are shown on Table 2.

Table 2 The recapitulation of coastal-polluted porcelain insulator experimental data.

\begin{tabular}{|c|c|c|c|c|c|c|c|c|c|c|c|c|c|c|}
\hline $\begin{array}{l}V_{\max } \\
(\mathrm{kV})\end{array}$ & $\begin{array}{l}I_{\max } \\
(\mathrm{uA})\end{array}$ & $\begin{array}{c}\mathrm{H} \\
(\%)\end{array}$ & $\begin{array}{c}\mathrm{T} \\
\left({ }^{\circ} \mathrm{C}\right)\end{array}$ & $\underset{(\mathrm{kPA})}{\mathrm{P}}$ & $\begin{array}{l}\text { PHA } \\
\text { (DEG) }\end{array}$ & $\begin{array}{c}\mathrm{COS} \\
(\mathrm{PHA})\end{array}$ & $\underset{(\mathrm{u} . \mathrm{A})}{\mathrm{Hl}}$ & $\begin{array}{c}\mathrm{H} 3 \\
(\mathrm{uA})\end{array}$ & $\begin{array}{c}\mathrm{H} 5 \\
(\mathrm{uA})\end{array}$ & $\begin{array}{c}\mathrm{H} 7 \\
(\mathrm{uA})\end{array}$ & $\begin{array}{c}\mathrm{H} 9 \\
\text { (uA) }\end{array}$ & $\begin{array}{l}\mathrm{Hll} \\
(\mathrm{uA})\end{array}$ & $\begin{array}{l}\mathrm{Hl} 3 \\
(\mathrm{uA})\end{array}$ & THD \\
\hline 25.2 & 26.4 & 68 & 25.2 & 0 & 60.7 & 0.49 & 21.93 & 0.248 & 3.11 & 0.79 & 0.297 & 0.580 & 0.133 & 0.15 \\
\hline 51.2 & 55.2 & 68 & 25.3 & 0 & 59.9 & 0.50 & 44.57 & 0.579 & 7.96 & 2.29 & 0.250 & 0.796 & 0.187 & 0.19 \\
\hline 66.4 & 71.2 & 68 & 25.2 & 0 & 59.7 & 0.50 & 57.74 & 0.696 & 11.12 & 2.73 & 0.213 & 0.835 & 0.2 & 0.20 \\
\hline 63.0 & 67.2 & 68 & 25.2 & 0 & 59.6 & 0.51 & 53.93 & 0.724 & 10.30 & 2.65 & 0.222 & 0.823 & 0.205 & 0.20 \\
\hline 52.1 & 54.4 & 68 & 25.2 & 0 & 61.2 & 0.48 & 43.51 & 0.590 & 8.17 & 2.39 & 0.139 & 0.810 & 0.176 & 0.20 \\
\hline 48.7 & 48.8 & 68 & 25.3 & 0 & 62.3 & 0.46 & 40.07 & 0.591 & 7.15 & 2.09 & 0.206 & \begin{tabular}{|l}
0.858 \\
\end{tabular} & 0.175 & 0.19 \\
\hline 44.5 & 45.6 & 68 & 25.3 & 0 & 62.0 & 0.47 & 36.87 & 0.532 & 6.48 & 1.88 & 0.219 & 0.842 & 0.173 & 0.19 \\
\hline 52.1 & 49.6 & 68 & 28.5 & 0.2 & 64.8 & 0.43 & 40.70 & 0.475 & 7.50 & 2.47 & 0.208 & 0.842 & 0.218 & 0.20 \\
\hline 52.1 & 47.2 & 68 & 30.7 & 0.0 & 65.8 & 0.41 & 38.54 & 0.467 & 7.39 & 2.46 & 0.143 & \begin{tabular}{|l}
0.767 \\
\end{tabular} & 0.227 & 0.20 \\
\hline 54.6 & 44.8 & 67 & 32.6 & 0.4 & 71.0 & 0.33 & 36.18 & 0.145 & 7.19 & 2.22 & 0.087 & \begin{tabular}{|l|l}
0.734 \\
\end{tabular} & 0.131 & 0.21 \\
\hline 54.6 & 40.8 & 67 & 35.6 & 0.2 & 71.0 & 0.33 & 34.69 & 0.212 & 7.02 & 2.27 & 0.059 & 0.714 & 0.152 & 0.21 \\
\hline 55.4 & 40.8 & 70 & 37.3 & 0.0 & 72.7 & 0.30 & 33.64 & 0.403 & 7.29 & 2.27 & 0.127 & \begin{tabular}{|l}
0.790 \\
\end{tabular} & 0.171 & 0.23 \\
\hline 55.4 & 41.6 & 70 & 39.9 & 0.0 & 74.3 & 0.27 & 32.73 & 0.370 & 7.28 & 2.22 & 0.089 & \begin{tabular}{|l|l}
0.763 \\
\end{tabular} & 0.149 & 0.23 \\
\hline 55.4 & 40.8 & 71 & 42.4 & 0.2 & 74.9 & 0.26 & 32.71 & 0.395 & 7.32 & 2.12 & 0.117 & 0.653 & 0.158 & 0.23 \\
\hline 55.4 & 39.2 & 70 & 45.0 & 0.0 & 74.3 & 0.27 & 32.66 & 0.410 & 7.40 & 2.12 & 0.088 & $\begin{array}{l}0.745 \\
\end{array}$ & 0.172 & 0.24 \\
\hline 55.4 & 40.8 & 70 & 43.9 & -2.0 & 76.6 & 0.23 & 32.49 & 0.409 & 7.34 & 2.15 & 0.096 & 0.648 & 0.157 & 0.24 \\
\hline 55.4 & 40.8 & 70 & 43.2 & -1.6 & 76.5 & 0.23 & 32.60 & 0.356 & 7.43 & 2.20 & 0.092 & \begin{tabular}{|l}
0.739 \\
\end{tabular} & 0.151 & 0.24 \\
\hline 55.4 & 40.8 & 69 & 42.3 & -1.2 & 76.5 & 0.23 & 32.58 & 0.399 & 7.38 & 2.24 & 0.059 & 0.796 & 0.152 & 0.24 \\
\hline 55.4 & 41.6 & 69 & 41.6 & -0.8 & 75.8 & 0.25 & 32.62 & 0.425 & 7.37 & 2.20 & 0.069 & 0.724 & 0.138 & 0.24 \\
\hline 55.4 & 41.6 & 69 & 40.5 & -0.4 & 76.3 & 0.24 & 32.61 & 0.352 & 7.40 & 2.19 & 0.036 & 0.753 & 0.163 & 0.24 \\
\hline 55.4 & 40.0 & 69 & 37.9 & -3.0 & 75.8 & 0.25 & 32.59 & 0.357 & 7.40 & 2.19 & 0.042 & 0.796 & 0.167 & 0.24 \\
\hline 55.4 & 40.8 & 69 & 36.6 & -4.0 & 75.8 & 0.25 & 32.57 & 0.410 & 7.35 & 2.19 & 0.031 & 0.797 & 0.177 & 0.24 \\
\hline 55.4 & 43.2 & 68 & 33.7 & -3.4 & 75.6 & 0.25 & 32.54 & 0.373 & 7.22 & 2.23 & 0.020 & \begin{tabular}{|l}
0.729 \\
\end{tabular} & 0.194 & 0.23 \\
\hline 55.4 & 40.0 & 68 & 31.1 & 4.0 & 75.9 & 0.24 & 32.91 & 0.443 & 7.09 & 2.31 & 0.140 & $\begin{array}{l}0.602 \\
\end{array}$ & 0.181 & 0.23 \\
\hline 55.4 & 40.0 & 68 & 31.1 & 3.0 & 75.4 & 0.25 & 32.84 & 0.394 & 7.08 & 2.43 & 0.102 & 0.646 & 0.209 & 0.23 \\
\hline 55.4 & 40.0 & 68 & 30.7 & 2.0 & 75.3 & 0.25 & 32.81 & 0.416 & 6.91 & 2.33 & 0.063 & 0.601 & 0.185 & 0.22 \\
\hline 55.4 & 39.2 & 68 & 30.5 & 1.6 & 75.9 & 0.24 & 32.83 & 0.426 & 6.94 & 2.35 & 0.127 & 0.595 & 0.176 & 0.22 \\
\hline 55.4 & 40.8 & 68 & 30.3 & 1.2 & 76.0 & 0.24 & 32.85 & 0.433 & 7.13 & 2.33 & 0.106 & 0.612 & 0.17 & 0.23 \\
\hline 55.4 & 39.2 & 68 & 30.1 & 0.8 & 76.2 & 0.24 & 32.80 & 0.431 & 7.19 & 2.33 & 0.117 & \begin{tabular}{|l}
0.627 \\
\end{tabular} & 0.244 & 0.23 \\
\hline 55.4 & 40.8 & 68 & 30.0 & 0.4 & 76.9 & 0.23 & 32.79 & 0.440 & 7.14 & 2.46 & 0.107 & \begin{tabular}{|l|l}
0.649 \\
\end{tabular} & 0.224 & 0.23 \\
\hline 26.5 & 194.0 & 76 & 24.5 & 0.2 & 23.0 & 0.92 & 182.64 & 2.320 & 12.32 & 4.31 & 1.570 & \begin{tabular}{|l}
1.720 \\
\end{tabular} & 0.693 & 0.07 \\
\hline 15.5 & 134.0 & 77 & 24.6 & 0.0 & 18.7 & 0.95 & 126.56 & 1.650 & 7.62 & 1.95 & 1.210 & 0.989 & 0.634 & 0.06 \\
\hline 15.5 & 178.0 & 78 & 25.0 & 0.0 & 14.4 & 0.97 & 166.90 & 2.190 & 9.69 & 1.95 & 1.110 & 1.090 & 0.809 & 0.06 \\
\hline 15.5 & 192.0 & 79 & 25.2 & 0.0 & 13.7 & 0.97 & 180.90 & 2.240 & 10.21 & 2.11 & 1.300 & 1.200 & 0.822 & 0.06 \\
\hline 10.8 & 158.0 & 83 & 25.5 & 0.0 & 12.1 & 0.98 & 151.58 & 1.870 & 6.99 & 1.14 & 0.805 & 0.754 & 0.548 & 0.05 \\
\hline 10.8 & 158.0 & 88 & 25.5 & 0.0 & 10.7 & 0.98 & 150.69 & 1.850 & 7.48 & 1.35 & 0.899 & 0.872 & 0.613 & 0.05 \\
\hline 10.8 & 158.0 & 89 & 25.5 & 0.0 & 11.5 & 0.98 & 149.87 & 1.890 & 7.68 & 1.41 & 0.960 & 0.757 & 0.68 & 0.05 \\
\hline 10.8 & 156.0 & 93 & 25.5 & 0.0 & 10.8 & 0.98 & 147.11 & 1.870 & 7.79 & 1.42 & 1.010 & 0.617 & 0.69 & 0.06 \\
\hline 10.8 & 148.0 & 97 & 25.0 & 0.0 & 11.6 & 0.98 & 141.30 & 1.750 & 7.52 & 1.25 & 0.916 & 0.835 & 0.641 & 0.06 \\
\hline 10.8 & 146.0 & 98 & 25.7 & 0.0 & 11.5 & 0.98 & 138.32 & 1.700 & 7.25 & 1.24 & 0.822 & 0.975 & 0.541 & 0.06 \\
\hline 10.8 & 128.0 & 99 & 25.6 & -0.4 & 12.6 & 0.98 & 121.16 & 1.430 & 6.81 & 1.21 & 0.748 & 0.728 & 0.566 & 0.06 \\
\hline 11.1 & 122.0 & 99 & 25.5 & -1.4 & 13.7 & 0.97 & 115.45 & 1.400 & 6.69 & 1.17 & 0.664 & 0.670 & 0.553 & 0.06 \\
\hline 11.1 & 134.0 & 99 & 25.4 & -3.0 & 12.3 & 0.98 & 125.32 & 1.530 & 7.14 & 1.27 & 0.857 & 0.761 & 0.57 & 0.06 \\
\hline 11.1 & 118.0 & 98 & 25.2 & -4.0 & 13.0 & 0.97 & 110.95 & 1.260 & 6.45 & 1.28 & 0.758 & 0.897 & 0.497 & 0.06 \\
\hline 11.1 & 128.0 & 98 & 25.6 & -2.8 & 12.3 & 0.98 & 119.87 & 1.480 & 6.80 & 1.19 & 0.713 & 0.649 & 0.522 & 0.06 \\
\hline 10.9 & 120.0 & 99 & 25.8 & -1.6 & 13.6 & 0.97 & 113.99 & 1.410 & 6.50 & 1.36 & 0.745 & 1.030 & 0.456 & 0.06 \\
\hline 10.9 & 120.0 & 99 & 25.9 & -1.2 & 12.9 & 0.97 & 112.45 & 1.390 & 6.22 & 1.24 & 0.701 & 0.892 & 0.464 & 0.06 \\
\hline 10.9 & 122.0 & 99 & 26.0 & -0.8 & 12.2 & 0.98 & 116.08 & 1.360 & 6.23 & 1.18 & 0.639 & 0.942 & 0.436 & 0.06 \\
\hline 11.1 & 170.0 & 88 & 26.2 & 1.2 & 9.4 & 0.99 & 163.32 & 2.160 & 8.14 & 0.99 & 0.941 & 0.674 & 0.51 & 0.05 \\
\hline 10.9 & 166.0 & 87 & 26.3 & 2.8 & 9.8 & 0.99 & 158.12 & 2.020 & 7.66 & 0.93 & 1.030 & 0.786 & 0.492 & 0.05 \\
\hline 11.1 & 162.0 & 86 & 26.3 & 3.6 & 9.3 & 0.99 & 154.17 & 2.010 & 7.43 & 1.03 & 0.930 & 0.756 & 0.482 & 0.05 \\
\hline 11.1 & 150.0 & 86 & 26.3 & 4.0 & 10.8 & 0.98 & 144.74 & 1.810 & 6.98 & 0.93 & 0.922 & 0.898 & 0.424 & 0.05 \\
\hline 10.9 & 246.0 & 77 & 32.6 & 0.0 & 7.2 & 0.99 & 237.64 & 3.900 & 11.86 & 1.89 & 1.720 & 0.740 & 0.885 & 0.05 \\
\hline 11.1 & 186.0 & 70 & 36.8 & 0.2 & 10.1 & 0.98 & 177.68 & 2.560 & 9.06 & 1.19 & 1.130 & 0.871 & 0.626 & 0.05 \\
\hline 11.1 & 160.0 & 69 & 37.0 & 0.0 & 10.8 & 0.98 & 151.09 & 2.190 & 7.84 & 1.16 & 1.060 & 0.750 & 0.625 & 0.06 \\
\hline 11.1 & 146.0 & 69 & 37.1 & & 12.3 & 0.98 & 136.94 & 1.800 & 7.52 & 1.31 & 0.873 & 0.920 & 0.631 & 0.06 \\
\hline 11.1 & 124.0 & 69 & 37.7 & 0.0 & 13.7 & 0.97 & 117.24 & 1.460 & 6.39 & 1.22 & 0.628 & 0.832 & 0.536 & 0.06 \\
\hline 10.9 & 114.0 & 69 & 38.1 & 0.0 & 15.1 & 0.97 & 106.33 & 1.420 & 5.87 & 1.24 & 0.708 & 0.877 & 0.519 & 0.06 \\
\hline 11.1 & 106.0 & 69 & 38.4 & 0.0 & 15.8 & 0.96 & 99.27 & 1.260 & 5.65 & 1.08 & 0.471 & 0.732 & 0.512 & 0.06 \\
\hline 11.1 & 92.0 & 69 & 38.7 & 0.0 & 16.6 & 0.96 & 85.85 & 1.040 & 4.94 & 0.93 & 0.375 & 0.642 & 0.397 & 0.06 \\
\hline 11.1 & 84.0 & 69 & 39.0 & 0.0 & 17.3 & 0.95 & 79.20 & 0.867 & 4.71 & 0.87 & 0.394 & 0.776 & 0.389 & 0.06 \\
\hline 11.1 & 74.0 & 69 & 39.2 & 0.0 & 18.7 & 0.95 & 69.24 & 0.761 & 4.21 & 0.91 & 0.305 & 0.746 & 0.321 & 0.06 \\
\hline
\end{tabular}




\subsection{Polluted Epoxy Resin Insulator}

Like as porcelain insulator, on the epoxy resin insulator, it is also shown two main conditions of leakage current measurement results, i.e. dry and wet conditions. In this case, the sample of dry condition was $49.6 \mathrm{kV}, 27.6^{\circ} \mathrm{C}, 68 \%$, and $0 \mathrm{kPa}$ of applied voltage, temperature, relative humidity and pressure respectively. In dry hermetically sealed chamber condition, the waveform of typical leakage current measurement of epoxy resin insulator in Bitmap form shown on Figure 8. This waveform is not so significantly different from that the previous dry condition of new-clean epoxy resin insulator. Thus, in dry condition, the pollutant stuck on porcelain insulator surface did not influence leakage current significantly.

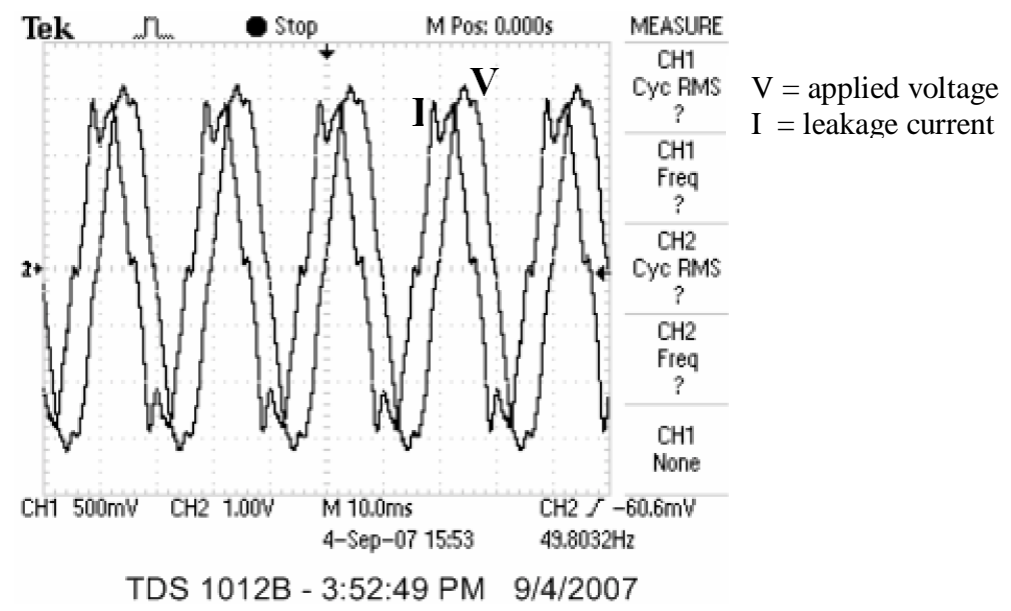

Figure 8 Bitmap form of applied voltage and leakage current waveforms of dry polluted epoxy resin insulator.

Whereas Figure 9 is Excel graphical form of applied voltage and leakage current waveforms of polluted epoxy resin insulator on Figure 8 condition. The applied voltage is pure sinusoidal waveform, that the magnitude values are mentioned on the right side. Otherwise, the magnitude values of leakage current wave are indicated on the left side. On this condition, the amplitude of leakage current and phase difference between leakage current and applied voltage are 96 $\mu \mathrm{A}$ and 76.8 degree respectively. It is indicated that the leakage current is very low, and the phase angle is so large. Thus, the insulator property is still capacitive. Based on this leakage current waveform, it will be analyzed the frequency spectrum using fast Fourier transform. 


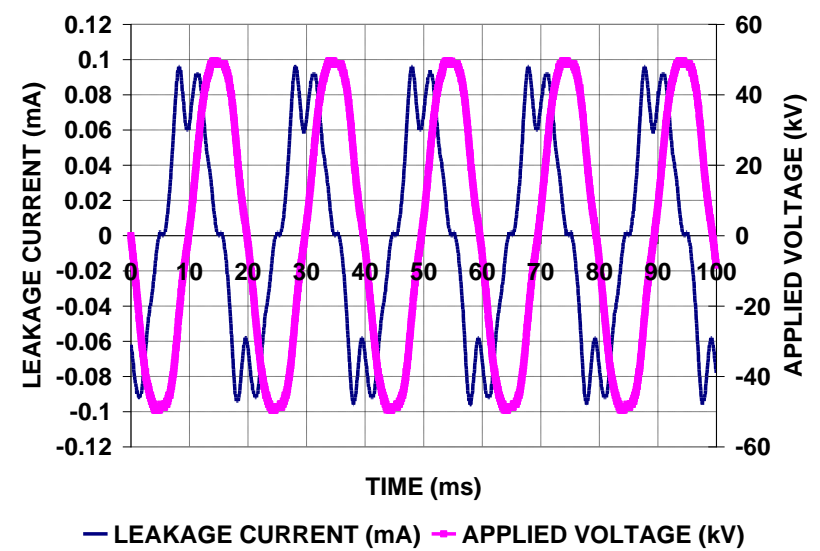

Figure 9 Excel graphical form voltage and leakage current waveforms of dry polluted epoxy resin insulator.

Figure 10 shows the frequency spectrum of leakage current waveform of Figure 9. In this condition, the first to thirteenth odd harmonics are $82.9 \%, 0.1 \%$, $17.7 \%, 5.9 \%, 0.6 \%, 1.4 \%, 0.3 \%$ respectively, compared to the leakage current amplitude. The third harmonic is very small, so that it still operated normally. Otherwise, the total harmonic distortion (THD) is $22.6 \%$, so that it is also normal condition.

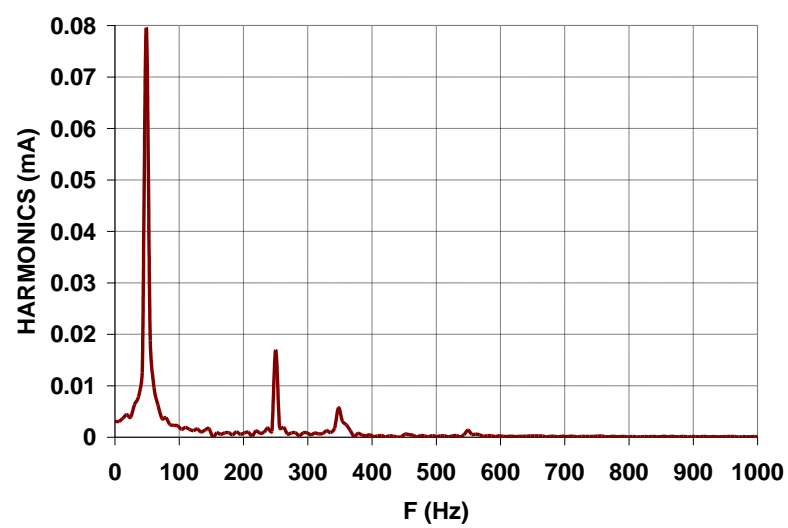

Figure 10 Frequency spectrum of leakage current waveforms of Figure 9.

On the other condition, Figure 11 shows Bitmap form of leakage current and applied voltage waveforms on polluted epoxy resin insulator due to $50.4 \mathrm{kV}$, $99 \%, 24^{\circ} \mathrm{C}, 0 \mathrm{kPa}$ of applied voltage, relative humidity, temperature and pressure respectively. Furthermore, Figure 12 is its Excel graphical form. This is as sample of wet condition. 


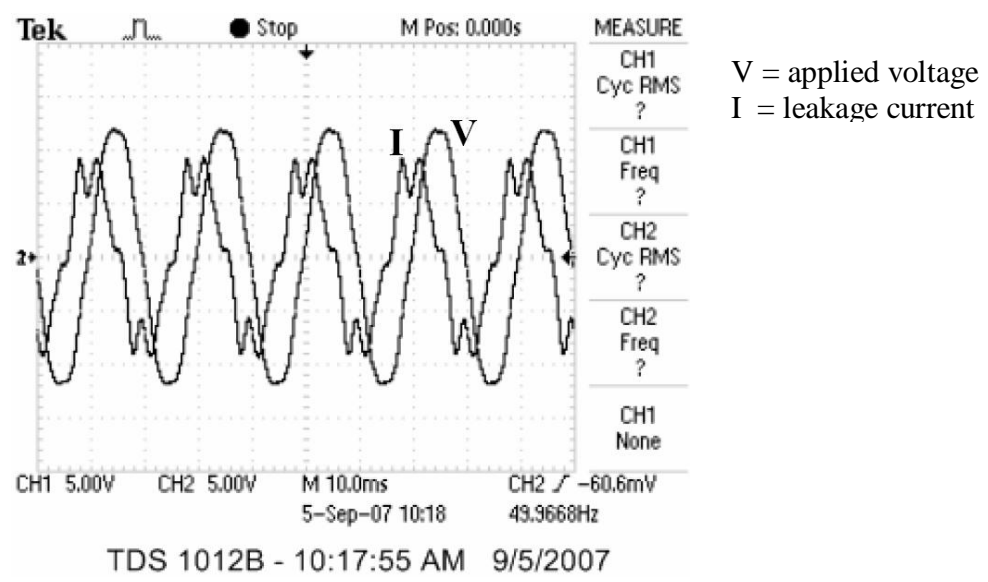

Figure 11 Bitmap form of applied voltage and leakage current waveforms of wet polluted epoxy resin insulator.

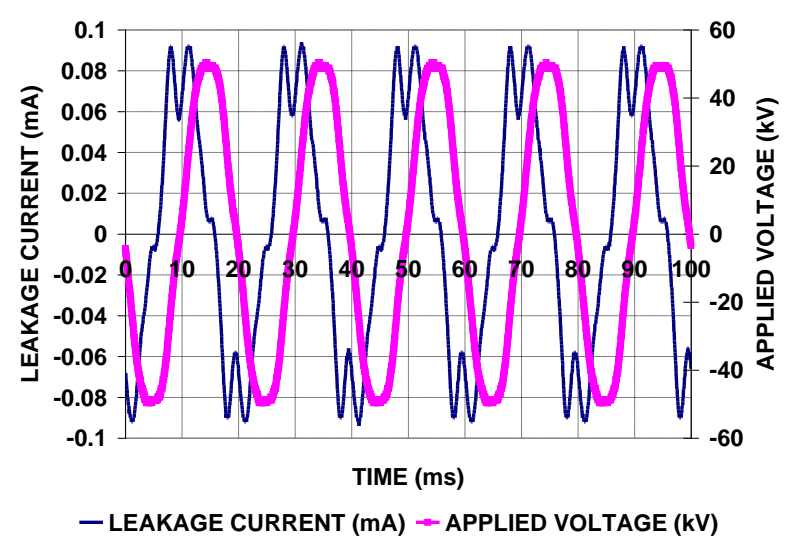

Figure 12 Excel graphical form voltage and leakage current waveforms of wet polluted epoxy resin insulator.

The applied voltage is pure sinusoidal waveform, that the magnitude values are mentioned on the right side. Otherwise, the magnitude values of leakage current wave are indicated on the left side. On this condition, the amplitude of leakage current and phase difference between leakage current and applied voltage are 92 $\mu \mathrm{A}$ and 68.9 degree respectively. It is indicated that the leakage current is very low, and the phase angle is just small difference, that is just around 7.9 degree lower than that the dry one. Thus, the insulator property is also still capacitive. This is also supported by indication of leakage current which still so far from sinusoidal waveform. Based on this leakage current waveform, it will be analyzed the frequency spectrum using fast Fourier transform. 


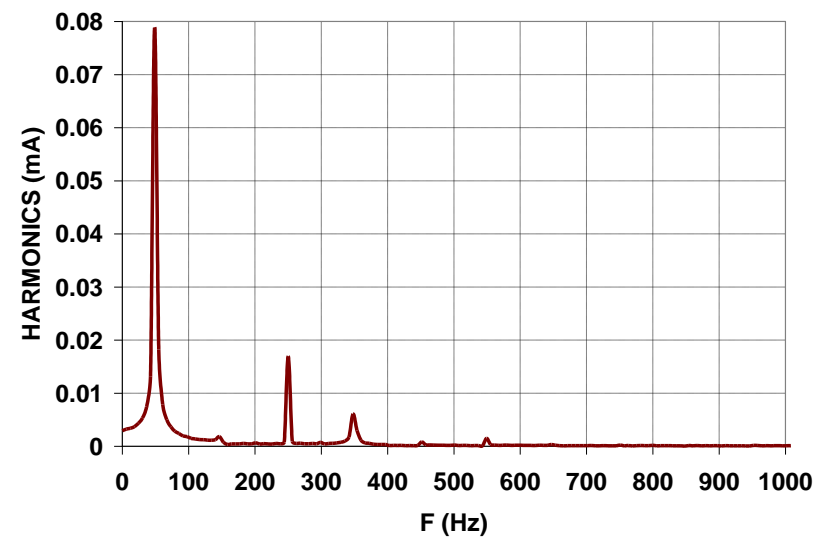

Figure 13 Frequency spectrum of leakage current waveforms of Figure 12.

Figure 13 shows the frequency spectrum of leakage current waveform of Figure 12. In this condition, the first to thirteenth odd harmonics are $85.7 \%, 0.8 \%$, $18.4 \%, 6.6 \%, 0.9 \%, 1.6 \%$ and $0.4 \%$ respectively, compared to the leakage current amplitude. The third harmonic is very small, so that it still operated normally. However, the first harmonic is fairly small higher rather than the dry one. Thus, actually it can be concluded that on the epoxy resin insulator in condition, the leakage current is fairly smaller influenced by wet relative humidity condition than that the porcelain one. Otherwise, the total harmonic distortion (THD) is $22.9 \%$, nearly same as the dry one, so that it is also normal condition.

Table 3 The levels of correlation among parameters on the polluted epoxy resin insulator.

\begin{tabular}{|c|c|c|c|c|c|c|c|c|c|c|c|c|c|c|c|}
\hline Varlables & $V_{\max }$ & $I_{\max }$ & H & $T$ & $\mathbf{P}$ & $\theta$ & $\cos (\theta)$ & H1 & $\mathrm{H} 3$ & H5 & $\mathrm{H} 7$ & $\mathrm{H9}$ & H11 & $\mathrm{H} 13$ & THD \\
\hline$V_{\max }$ & 1.00 & 0.82 & -0.04 & -0.01 & 0.00 & -0.10 & 0.10 & 0.69 & 0.81 & 0.75 & 0.54 & -0.03 & 0.49 & 0.29 & 0.81 \\
\hline $\begin{array}{l}I_{\max } \\
\mathrm{H}\end{array}$ & $\begin{array}{r}0.82 \\
-0.04\end{array}$ & $\begin{array}{l}1.00 \\
0.25\end{array}$ & $\begin{array}{l}0.25 \\
1.00\end{array}$ & $\begin{array}{l}-0.22 \\
-0.57\end{array}$ & $\begin{array}{r}0.00 \\
-0.07\end{array}$ & $\begin{array}{r}0.18 \\
-0.08\end{array}$ & $\begin{array}{r}-0.17 \\
0.09\end{array}$ & $\begin{array}{l}0.97 \\
0.39\end{array}$ & $\begin{array}{r}0.44 \\
-0.25\end{array}$ & $\begin{array}{l}0.98 \\
0.36\end{array}$ & $\begin{array}{l}0.88 \\
0.44\end{array}$ & $\begin{array}{l}0.47 \\
0.63\end{array}$ & $\begin{array}{l}0.79 \\
0.37\end{array}$ & $\begin{array}{l}0.55 \\
0.49\end{array}$ & $\begin{array}{l}0.91 \\
0.26\end{array}$ \\
\hline$T$ & -0.01 & -0.22 & -0.57 & 1.00 & 0.08 & 0.25 & -0.26 & -0.24 & 0.06 & -0.29 & -0.31 & -0.34 & -0.26 & -0.19 & -0.31 \\
\hline $\mathbf{P}$ & 0.00 & 0.00 & -0.07 & 0.08 & 1.00 & 0.08 & -0.08 & 0.00 & 0.08 & 0.00 & 0.06 & 0.16 & -0.10 & 0.23 & 0.01 \\
\hline$\theta$ & -0.10 & 0.18 & -0.08 & 0.25 & 0.08 & 1.00 & -1.00 & 0.32 & -0.51 & 0.22 & 0.46 & 0.44 & 0.30 & 0.41 & 0.15 \\
\hline $\cos (\theta)$ & 0.10 & -0.17 & 0.09 & -0.26 & -0.08 & -1.00 & 1.00 & -0.32 & 0.51 & -0.21 & -0.46 & -0.44 & -0.30 & -0.40 & -0.15 \\
\hline H1 & 0.69 & 0.97 & 0.39 & -0.24 & 0.00 & 0.32 & -0.32 & 1.00 & 0.24 & 0.99 & 0.96 & 0.63 & 0.82 & 0.66 & 0.87 \\
\hline $\mathrm{H} 3$ & 0.81 & 0.44 & -0.25 & 0.06 & 0.08 & -0.51 & 0.51 & 0.24 & 1.00 & 0.34 & 0.06 & -0.41 & 0.08 & -0.01 & 0.45 \\
\hline H5 & 0.75 & 0.98 & 0.36 & -0.29 & 0.00 & 0.22 & -0.21 & 0.99 & 0.34 & 1.00 & 0.93 & 0.57 & 0.80 & 0.63 & 0.93 \\
\hline $\mathrm{H} 7$ & 0.54 & 0.88 & 0.44 & -0.31 & 0.06 & 0.46 & -0.46 & 0.96 & 0.06 & 0.93 & 1.00 & 0.77 & 0.82 & 0.76 & 0.86 \\
\hline H9 & -0.03 & 0.47 & 0.63 & -0.34 & 0.16 & 0.44 & -0.44 & 0.63 & -0.41 & 0.57 & 0.77 & 1.00 & 0.60 & 0.72 & 0.42 \\
\hline H11 & 0.49 & 0.79 & 0.37 & -0.26 & -0.10 & 0.30 & -0.30 & 0.82 & 0.08 & 0.80 & 0.82 & 0.60 & 1.00 & 0.54 & 0.71 \\
\hline H13 & 0.29 & 0.55 & 0.49 & -0.19 & 0.23 & 0.41 & -0.40 & 0.66 & -0.01 & 0.63 & 0.76 & 0.72 & 0.54 & 1.00 & 0.56 \\
\hline THD & 0.81 & 0.91 & 0.26 & -0.31 & 0.01 & 0.15 & -0.15 & 0.87 & 0.45 & 0.93 & 0.86 & 0.42 & 0.71 & 0.56 & 1.00 \\
\hline
\end{tabular}


The behaviors of parameters on the measurements of polluted epoxy resin insulator are shown on Table 3. First to last columns are maximum applied voltage, maximum leakage current, relative humidity, temperature, pressure, phase difference between leakage current and applied voltage waves, cosine of phase difference, first to thirteenth odd harmonics, and total harmonic distortion (THD) respectively. The actual data of pressure in chamber were positive and negative. The positive pressure means the chamber was compressed, and the negative pressure means the chamber was sucked, using electric pumps. Based on this correlation matrix, the relative humidity did not significant to influence to the leakage current magnitude and the phase difference between leakage current and applied voltage. These are only $25 \%$ and $-8 \%$ respectively. This gives explanation that the relative humidity enhanced the maximum leakage current and reduced phase angle slightly. Otherwise, the applied voltage influenced to the leakage current was still considerable, that is $82 \%$.

Table 4 The recapitulation of coastal-polluted epoxy resin insulator experimental data.

\begin{tabular}{|c|c|c|c|c|c|c|c|c|c|c|c|c|c|c|}
\hline $\begin{array}{l}V_{\max } \\
(\mathrm{kV})\end{array}$ & $\begin{array}{l}I_{\max } \\
(\mu \mathrm{A})\end{array}$ & $\begin{array}{c}\mathrm{H} \\
(\%)\end{array}$ & & & $\begin{array}{c}\Theta \\
(\mathrm{DEG})\end{array}$ & $\begin{array}{c}\cos \\
(\Theta)\end{array}$ & $\mathrm{H} 1(\mu \mathrm{A})$ & $\mathrm{H} 3(\mu \mathrm{A})$ & $\mathrm{H} 5(\mu \mathrm{A})$ & $\mathrm{H} 7(\mu \mathrm{A})$ & $\mathrm{H} 9(\mu \mathrm{A})$ & $\mathrm{H} 11(\mu \mathrm{A})$ & $\mathrm{H} 13(\mu \mathrm{A})$ & THD \\
\hline 49.6 & 0.096 & 68 & 27.6 & 0 & & 0.229 & $796 \mathrm{E}-02$ & $8.67 \mathrm{E}-05$ & $70 \mathrm{E}-02$ & 71E-03 & $5.96 \mathrm{E}-04$ & $37 \mathrm{E}-03$ & $42 E-04$ & $22.6 \%$ \\
\hline & & 8 & & 0 & & & & & & & & & & \\
\hline & 40 & & 6 & 0 & & & & & & & & & & \\
\hline & 55 & & & & & & & & & & & & & \\
\hline & 096 & 8 & 27.6 & 0 & & & & & & & & & & \\
\hline 48.7 & 066 & 68 & 7.6 & 0 & 7.0 & 224 & & & & & & & & \\
\hline 70.6 & 116 & 68 & 27.6 & 0 & 3.6 & 522 & & & & & & & & \\
\hline 77.3 & 130 & 68 & 27.6 & 0 & & 491 & & & & & & & & $26.2 \%$ \\
\hline 50.4 & 098 & 78 & 22.9 & 0.2 & & 225 & & & & & & & & 9 \\
\hline 50.4 & 098 & 0 & 23 & & & 249 & & & & & & & & .2 \\
\hline & 0 & 3 & 2.2 & & & 290 & & & & & & & & \\
\hline 50.4 & 096 & 87 & 3.3 & & & 323 & & & & & & & & \\
\hline 49.6 & 094 & 90 & 23.3 & 2 & & 326 & & & & & & & & $23.4 \%$ \\
\hline & 094 & 93 & .5 & 2 & & 333 & & & & & & & & $0 \%$ \\
\hline 0.4 & 094 & & 23.6 & & & 335 & & & & & & & & $3.1 \%$ \\
\hline 9.6 & 92 & & 3. & & & 337 & & & & & & & & 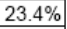 \\
\hline 50.4 & 094 & 98 & 23.8 & 0.2 & & 345 & & & & & & & & $8 \%$ \\
\hline 50.4 & 092 & 99 & 24 & & & 359 & & & & & & & & $22.9 \%$ \\
\hline & 096 & 83 & 6 & -2.2 & & 229 & & & & & & & & $22.6 \%$ \\
\hline & 096 & 8 & 26 & -3 & & 234 & & & & & & & & \\
\hline 4 & 096 & & 26 & -3.6 & & 236 & & & & & & & & $23.2^{\circ}$ \\
\hline 49.6 & 096 & & 26 & & & & & & & & & & & $5.0 \%$ \\
\hline 49.6 & 096 & & 26 & & & 212 & & & & & & & & $3.5 \%$ \\
\hline 49.6 & 096 & 78 & 26.1 & -4.8 & & 226 & & & & & & & & $23.2 \%$ \\
\hline & 096 & & & 1.6 & & 0.227 & & & & & & & & $23.0 \%$ \\
\hline & 09 & & & & & & & & & & & & & \\
\hline 4 & 096 & & & & & 195 & & & & & & & & $22.7 \%$ \\
\hline 49.6 & 096 & 77 & 27.3 & 4.6 & & 217 & & & & & & & & $23.2 \%$ \\
\hline 49.6 & 0.096 & 77 & 27.1 & 5 & 79.8 & 0.178 & -02 & -04 & -02 & & $=-04$ & & $E-04$ & $23.2 \%$ \\
\hline 49.6 & 0.096 & 77 & & & & 168 & & & & & & & -04 & $23.3 \%$ \\
\hline 49.6 & 0.094 & & & & & & & & & & & & & \\
\hline 49.6 & 090 & & & & & & & & & & & & & $22.5 \%$ \\
\hline & 0 & & & & & & & & & & & & -04 & $22.4 \%$ \\
\hline & 0.086 & 69 & 4 & 0.2 & & 150 & & & & & & & -04 & $22.4 \%$ \\
\hline & 0.070 & & 43.2 & 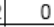 & 75.6 & 0.249 & $6.10 \mathrm{E}-02$ & $5.84 \mathrm{E}-04$ & 1.22 & 4.22 & $4.02 \mathrm{E}-\mathrm{U} 4$ & 1.1 & 75 & \\
\hline
\end{tabular}


This phenomenon occurred due to epoxy resin insulator surface made water droplets of humidity tend to be small spots, rather than to spread out or blot. Thus, on this condition, the leakage current was still dominated by applied voltage. Furthermore, the leakage current magnitude determined the magnitude of harmonics. Generally, the harmonics have a high correlation to the leakage current amplitude. Otherwise, the complete recapitulation data of measurements on polluted epoxy resin insulator on this condition are shown on Table 4.

\subsection{Test Results of SEM and EDAX}

\subsubsection{New and Clean Specimens}

Visual inspections on insulator specimen surfaces and sticky pollutants on insulator surfaces were conducted using SEM (scanning electron microscope). The tested insulator specimens were exactly same materials as the insulator samples accordingly. Whereas the pollutants were removed or scraped using a cutter from insulator sticky pollutants.

A qualitative estimation of the extent of degradation can be made by visual inspection alone and these can be examined in detail by SEM. Cracks and pits can easily be observed on the surfaces. SEM imaging can, therefore, provide a qualitative estimate of both the type and extent of a degradation [9].

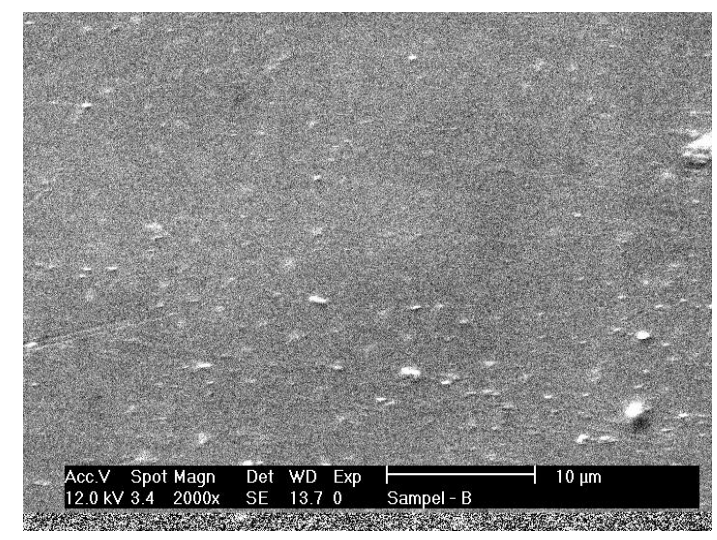

Figure 14 Typical SEM test result on the surface of new-clean porcelain insulator specimen.

Figure 14 shows a surface of new-clean porcelain insulator specimen using SEM with magnification 2000 times. It is seen that the surface is very smooth. Whereas Figure 15 shows the magnifying surface of new-clean epoxy resin insulator specimen. The magnifying level is same as previous, i.e. 2000 times to the actual condition. 


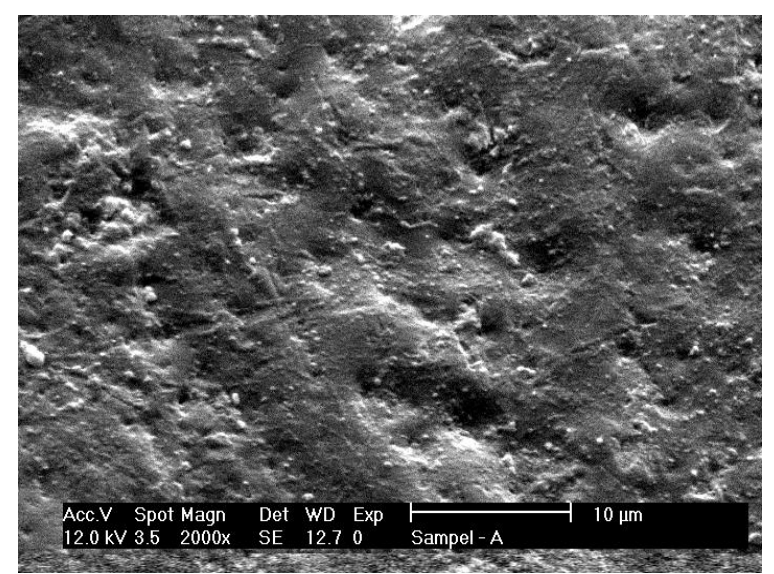

Figure 15 Typical SEM test result on the surface of new-clean porcelain insulator specimen.

It is seen the new-clean epoxy resin insulator specimen surface is rougher than the porcelain one. It is reasonable that on porcelain surface was coated by glazing [3]. Whereas, the epoxy resin surface was coated by silicone-based mould for providing of hydrophobic surface [4].

\subsubsection{Coastal Polluted Porcelain Insulator Specimen}

Figure 16(a) and 16(b) show typical SEM test results of polluted specimen. The specimen was one piece, however, the taking picture was twice. These show that the surface rather different from the new-clean one (Figure 14). Typically the surface became dirty, and fairly rougher. This is reasonable due to existence of pollutant on the surface of specimen.

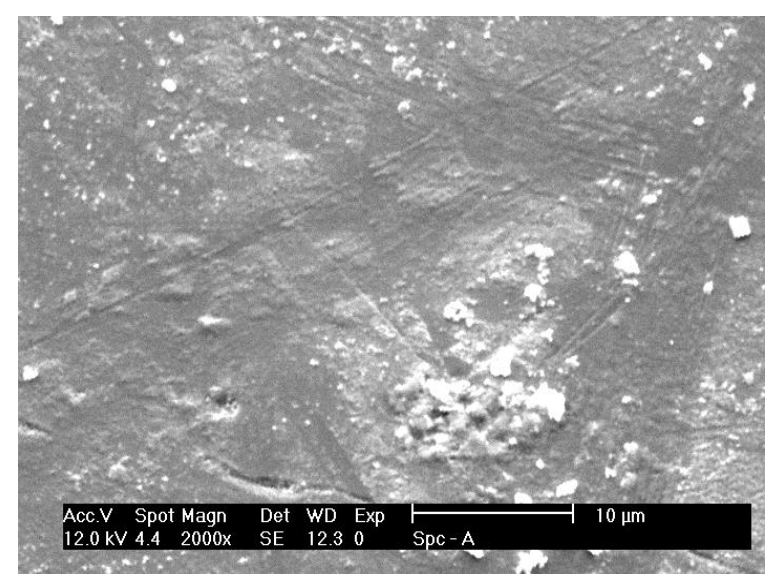

(a) 


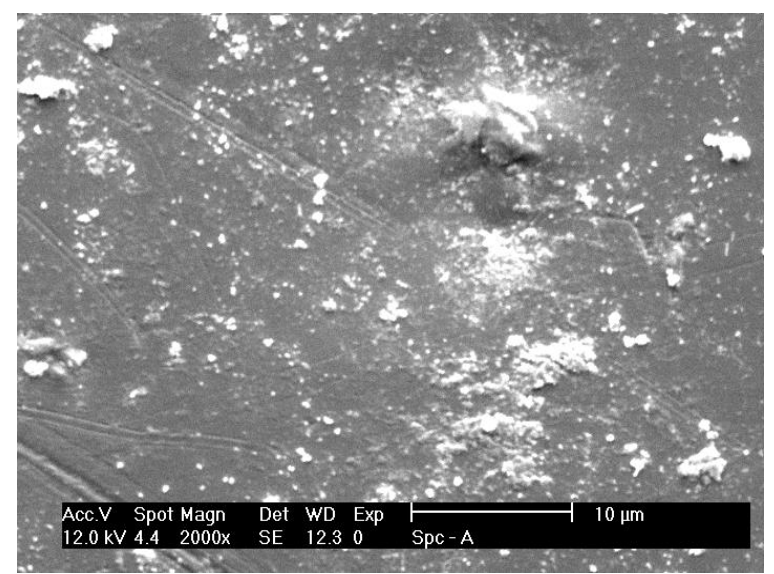

(b)

Figure 16 Typical SEM test result on the surface of polluted porcelain insulator specimen.

However, generally the surface was still smooth. This mean the glazing of porcelain surface was not significant influenced by environmental conditions on this coastal area.

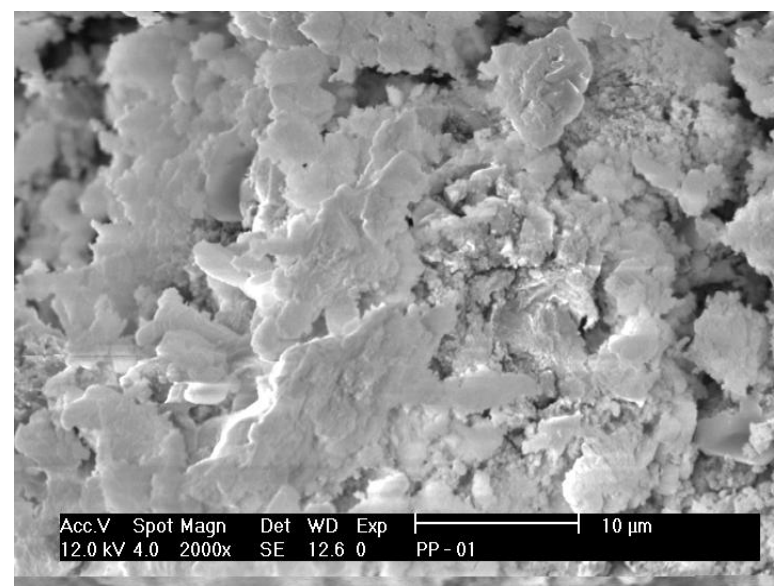

Figure 17 Typical SEM test result of pollutant on polluted porcelain insulator.

Figure 17 shows a typical SEM test result of pollutant on polluted porcelain insulator. The pollutant was scraped from the polluted porcelain insulator surface. It is seen that the pollutant not so clayey, because it was scraped from the insulator glaze, that the nearly all of glaze part was not included by scraping. Besides that, due to the glaze was very hard, so that the pollutant did not mix with it physically or chemically. 
Table 5 Test result of EDAX on pollutant of porcelain insulator surface.

\begin{tabular}{ccccc}
\hline No. & Elements & $\begin{array}{c}\text { First Test } \\
(\boldsymbol{\%})\end{array}$ & $\begin{array}{c}\text { Second } \\
\text { Test }(\boldsymbol{\%})\end{array}$ & $\begin{array}{c}\text { Everage } \\
(\boldsymbol{\%})\end{array}$ \\
\hline 1 & $\mathrm{Cl}$ & 28.82 & 34.01 & 31.42 \\
2 & $\mathrm{Si}$ & 20.29 & 13.34 & 16.82 \\
3 & $\mathrm{Fe}$ & 14.81 & 17.78 & 16.30 \\
4 & $\mathrm{Ca}$ & 13.38 & 15.10 & 14.24 \\
5 & $\mathrm{Na}$ & 10.97 & 10.60 & 10.79 \\
6 & $\mathrm{Al}$ & 8.79 & 4.84 & 6.82 \\
7 & $\mathrm{~K}$ & 2.94 & 4.33 & 3.64 \\
\hline
\end{tabular}

Table 5 shows the list of major chemical elements of EDAX test result contained in the pollutant scraped from the polluted porcelain insulator surface. This is reasonable the most dominant pollutant found was Chlorine, due to effect of marine. This is also most agreement with the previous one. Typically this elemen $\mathrm{t}$ is in some composition forms, such as $\mathrm{NaCl}, \mathrm{AlCl}_{3}, \mathrm{CaCl}_{2}, \mathrm{KCl}$ and $\mathrm{MgCl}_{2}$ [2].

The second one is Silicon that usually in form of $\mathrm{SiO}_{2}$. Generally, this compound is from dust of soil, that soil is mostly contained of Silicon. Whereas, Ferrum is supposed origin from metals around insulator, soil or stone, including concrete.

\subsubsection{Coastal Polluted Epoxy Resin Insulator Specimen}

Figure 18(a) and 18(b) show typically SEM test result of polluted epoxy resin insulator specimen. The surfaces were rougher rather than the new-clean one. This is caused by two parameters, one is pollutant stuck on the surface and another one due to scratch or pits. As the property of the siliconed epoxy resin surface, the smoothness of surface will be reduced due to environmental effects, including sun ray. Thus, it is reasonable that the polluted epoxy resin insulator be rougher rather than the polluted porcelain insulator specimen.

Whereas, Figure 19 shows the SEM test result of pollutant scraped from epoxy resin insulator surface. It is seen the pollutant is more clayey compared to the pollutant scraped from polluted porcelain insulator. This phenomenon was caused by the pollutant mixed to the silicone coating on insulator surface. This was naturally occurred or manually occurred when scraped the pollutant. 


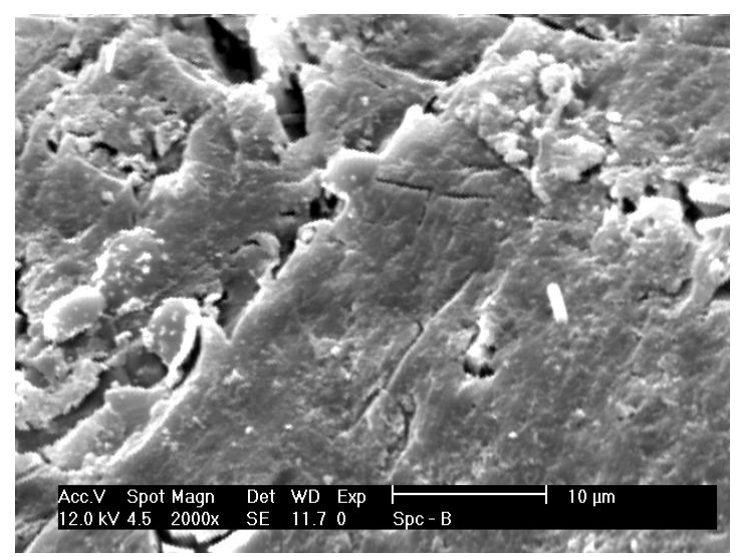

(a)

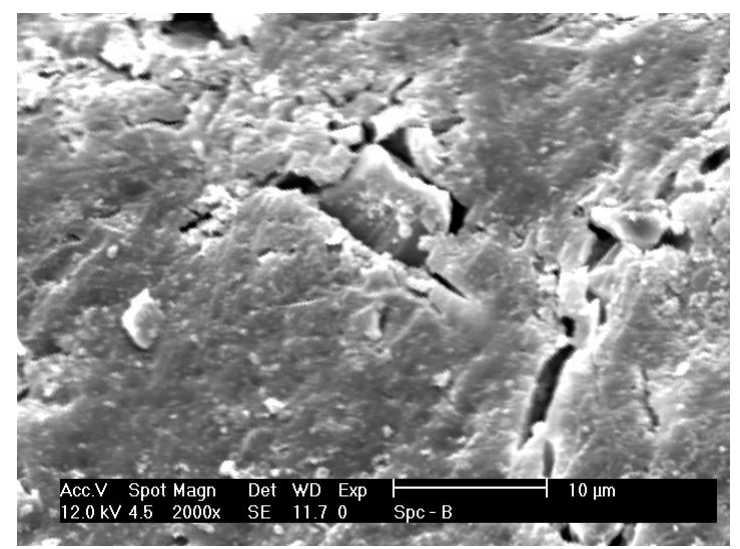

(b)

Figure 18 Typical SEM test result on the surface of polluted epoxy resin insulator specimen.

Otherwise, Table 6 shows test result of EDAX on pollutant of epoxy resin insulator surface. Although the most chemical compound was silicon chemical element. Chlorine was still major element of pollutant. This Chlorine was usually in composition of $\mathrm{NaCl}, \mathrm{MgCl}_{2}, \mathrm{AlCl}_{3}, \mathrm{KCl}$ and $\mathrm{CaCl}_{2}$. Silicon chemical element became the most was caused by soil dust and/or added by insulator material itself. 


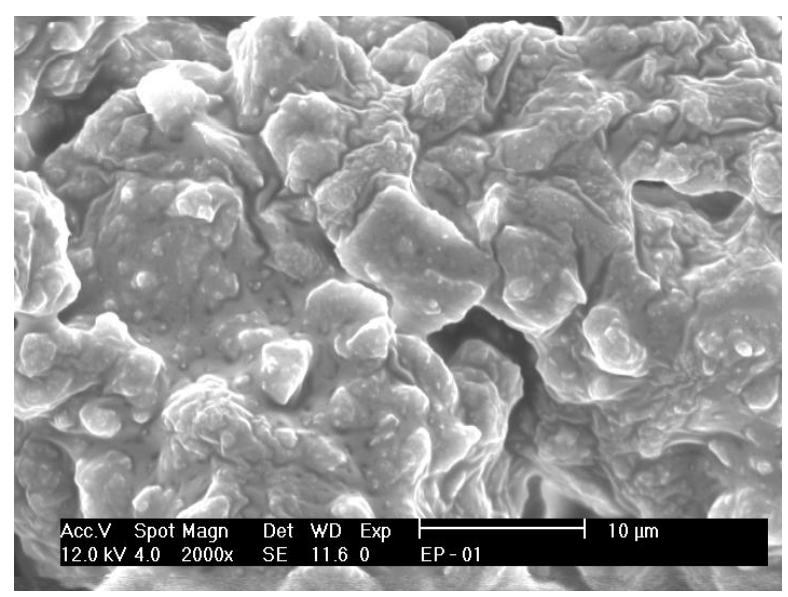

Figure 19 Typical SEM test result of pollutant on polluted epoxy resin insulator.

Table 6 Test result of EDAX on pollutant of epoxy resin insulator surface.

\begin{tabular}{ccccc}
\hline No. & Elements & $\begin{array}{c}\text { First Test } \\
(\mathbf{\%})\end{array}$ & $\begin{array}{c}\text { Second } \\
\text { Test }(\boldsymbol{\%})\end{array}$ & $\begin{array}{c}\text { Everage } \\
(\mathbf{\%})\end{array}$ \\
\hline 1 & $\mathrm{Si}$ & 34.10 & 34.95 & 34.53 \\
2 & $\mathrm{Cl}$ & 24.49 & 28.18 & 26.34 \\
3 & $\mathrm{Fe}$ & 12.21 & 11.36 & 11.79 \\
4 & $\mathrm{Ca}$ & 9.15 & 10.70 & 9.93 \\
5 & $\mathrm{Na}$ & 7.85 & 6.79 & 7.32 \\
6 & $\mathrm{Al}$ & 6.32 & 4.65 & 5.49 \\
7 & $\mathrm{Mg}$ & 3.69 & 1.59 & 2.64 \\
8 & $\mathrm{~K}$ & 2.02 & 1.79 & 1.91 \\
\hline
\end{tabular}

\section{Conclusion}

Based on the research data and analysis of the eight month coastal polluted porcelain and epoxy resin insulator leakage current measurements, it can be concluded that the polluted porcelain insulator was very susceptible to high relative humidity. This phenomenon was indicated by significant rise of the leakage current amplitudes and by a rapid reduction of the phase difference between leakage current and applied voltage waves in high relative humidity. These are also represented by components of the correlation matrix, 0.60 and 0.68 respectively.

Otherwise, on the polluted epoxy resin insulator, the relative humidity did not influence to the leakage current amplitude and phase difference between leakage current and applied voltage waves significantly. The components of 
correlation matrix are only 0.25 and -0.08 respectively. Thus, it is concluded that the polluted epoxy resin insulator more immune to contamination rather than the porcelain insulator.

Based on the test results of SEM, the epoxy resin insulator specimen surface was rougher than the porcelain one. This was occurred due to the epoxy resin surface had been coated by silicone, otherwise the porcelain surface had been coated by glaze, due to the glaze more endurable than silicone. Whereas the most chemical element of pollutant was Chlorine, due to influence of coast or marine, and followed by Silicon due to influence of surrounding soil and/or insulators theirselves.

\section{Acknowledgment}

Authors herewith respectfully offer thanks to scholarship of Postgraduate Education of Indonesia Government and PLN Research and Development, for supporting this research.

\section{References}

[1] Fernando, M.M.A.R., Performance for Non-ceramic Insulators in Tropical Environments, PhD Dissertation, Department of Electric Power Engineering, Chalmers University of Technology, Goteborg-Sweden, pp.1-2, 1999.

[2] Vosloo, W.L., A Comparison of the Performance of High-Voltage Insulator Materials in a Severely Polluted Coastal Environment, $\mathrm{PhD}$ Dissertation, Department of Electrical and Electronic Engineering, University of Stellenbosch, South Africa, March, pp.9-10, 2002.

[3] Gorur, R.S., Cherney, E.A., Burnham, J.T., Outdoor Insulators Ravi S. Gorur, Inc., Phoenix, Arizona, USA, pp.37, 145, 1999.

[4] Vosloo, W.L., Macey, R.E., Toureil, C. de, The Practical Guide to Outdoor High Voltage Insulators, Crown Publications CC., Johannesburg, South Africa, pp.36-37, 67, 2004.

[5] Suwarno, Leakage Current Waveforms of Outdoor Polymeric Insulators and Possibility of Application for Diagnostics of Insulator Conditions, Journal of Electrical Engineering \& Technology, The Korean Institute of Electrical Engineering, 1(1), pp.114-119, 2006.

[6] OriginLab Co., Origin V75 User's Manual, OriginLab Corporation, MA, USA, pp.601-611, 2003.

[7] Anderson, T.W., An Introduction to Multivariate Statistical Analysis, Second Edition, John Wiley \& Sons, pp.18,489, 1984.

[8] Whittaker, J., Graphical Models in Applied Multivariate Statistics, John Wiley \& Sons, pp.17,48-51, 1996. 
[9] Liu, H., Cash, G., Birthwhistle, D., George, G., Characterization of a Severely Degraded Silicone Elastomer HV Insulator -an Aid to Development of Lifetime Assessment Techniques, IEEE Transactions on Dielectrics and Electrical Insulation, Vol.12, No.3, pp.481, 485, June 2005. 